\title{
The emerging role of non-radiation endoscopic management of biliary tract disorders
}

\author{
Andrew Ofosua, Daryl Ramaia, Tagore Sunkaraa ${ }^{a}$, Douglas G. Adler ${ }^{\mathrm{b}}$ \\ The Brooklyn Hospital Center, NY; University of Utah School of Medicine, Huntsman Cancer Center, Salt Lake City, \\ Utah, USA
}

\begin{abstract}
Endoscopic retrograde cholangiopancreatography (ERCP) has evolved from a diagnostic and therapeutic technique into a therapeutic-centered modality for managing biliary disorders. Despite its many therapeutic benefits, radiation exposure from ERCP fluoroscopy is of concern and should be minimized as much as possible. Although the use of personal equipment offers significant protection against radiation, attention has been given to the development of non-radiation-based ERCP techniques. To this end, digital cholangioscopy and endoscopic ultrasound-assisted ERCP have emerged as alternatives to standard ERCP. Both techniques have sufficient feasibility and potential diagnostic accuracy to eliminate the need for fluoroscopy. Here we discuss the advances in non-radiation ERCP techniques and their role in the management of biliary stones.
\end{abstract}

Keywords Endoscopic retrograde cholangiopancreatography, non-radiation ERCP, fluoroscopy, digital cholangioscopy, endoscopic ultrasound-assisted ERCP

Ann Gastroenterol 2018; 31 (4): 1 - 5

\section{Introduction}

Endoscopic retrograde cholangiopancreatography (ERCP) is established as a therapeutic procedure for treating a variety of pancreatic and biliary duct disorders, most commonly the removal of bile duct stones and the relief of malignant obstructive jaundice [1-3]. Despite its many therapeutic benefits, ERCP with fluoroscopy places patients and staff at risk of some degree of exposure to ionizing radiation [4]. Reports indicate that radiation exposure or fluoroscopy time may vary according to institutional ERCP volume, user experience, and case complexity [5-7]. However, according to the ALARA principle (As Low As Reasonably Achievable), reducing the level of patients' and users' radiation exposure is a safety goal. As a result, there

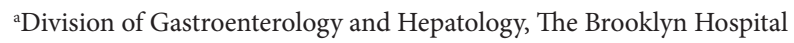
Center, NY (Andrew Ofosu, Daryl Ramai, Tagore Sunkara); ${ }^{b}$ Division of Gastroenterology and Hepatology, University of Utah School of Medicine, Huntsman Cancer Center, Salt Lake City, Utah (Douglas G. Adler), USA

\section{Conflict of Interest: None}

Correspondence to: Andrew Ofosu, MD, MPH, Division of Gastroenterology and Hepatology, The Brooklyn Hospital Center, 121 Dekalb Avenue, Brooklyn, New York 11201, USA, e-mail: andyofosu@ gmail.com

Received 27 April 2018; accepted 14 May 2018; published online 19 June 2018

DOI: https://doi.org/10.20524/aog.2018.0283 has been interest in the use of non-radiation-based ERCP modalities [8].

\section{Radiation-based ERCP}

Energy from a source that travels in the form of waves or particles is generally known as radiation. This energy has the capacity to interact with electrons, which results in the production of charged particles, such as alpha, beta and gamma, and X-rays. The use of fluoroscopy during ERCP procedures places endoscopists at risk for radiation-induced injury $[9,10]$. Radiation exposure can lead to direct cellular damage or to the production of reactive oxygen species that can cause indirect cell damage $[11,12]$. The severity of radiation-induced skin injury is dependent on the cell cycle, differentiation, tissue type, age, and internal or external microenvironments [13].

The effects of radiation are potentially cumulative [14]. However, for ERCP personnel, the risk is minimal if adequate protection is utilized. The International Commission on Radiological Protection (ICRP) recommends that total-body radiation exposure not exceed $50 \mathrm{mSv}$ per year [15]. Additionally, the United States Nuclear Regulatory Commission recommends that optic radiation not exceed 150 $\mathrm{mSv}$. Examining the level of whole-body radiation exposure, Naidu et al reported that 61 ERCP procedures produced an effective dose received by endoscopists ranging between 3.35 and $5.87 \mathrm{mSv}$ [16]. Additional studies assessing radiation dose according to the number of ERCPs and the anatomical site 
are summarized in Table 1 [16-21]. A review of these studies shows a wide range of radiation dosages and inconsistencies in the reporting. These may be due to the number of procedures performed, provider experience, low- or high-volume institutions and procedural complexity [22].

Various measures with the goal of mitigating radiation exposure during ERCP have been described, including reducing fluoroscopy time and enhancing fluoroscopy unit variables (e.g. pulse rate, magnification, collimation) and the use of adequate shielding [4,23]. In contrast to continuous fluoroscopy, pulse fluoroscopy enables endoscopists to adjust the dosage of radiation every second. Similarly, choosing a lower magnification mode results in lower exposure, while the use of a collimator reduces the scattering of radiation beams. Most ERCPs can be safely performed on mid-to-low magnification settings, with high magnification settings used only if needed for specific maneuvers. Additionally, endoscopists should wear lead aprons, thyroid shields, and radioprotective eyewear that protects against the harmful effects of radiation.

To further reduce the level of radiation exposure, especially in pregnant women and children, there has been a growing interest in the use of radiation-free techniques. The first report of a radiation-free ERCP was described in 1990, when an impacted ampullary stone was freed by performing a needleknife sphincterotomy [24]. Since then, several case reports and case series have described the use of radiation-free ERCP. Two major techniques have been reported in the literature, namely, digital cholangioscopy (DCS) and endoscopic ultrasound (EUS)-assisted ERCP.

\section{Non-radiation ERCP}

\section{EUS-based ERCP}

EUS-assisted ERCP without fluoroscopy often begins with an EUS examination to obtain and verify the presence of strictures or stones, together with their size, location and number $[25,26]$. If a stone is found, ERCP can be performed with a duodenoscope without using fluoroscopy. Biliary cannulation is attempted without the use of fluoroscopy, using a cannula or papillotome with or without a guidewire. Successful biliary cannulation is usually based on deep catheter insertion (at least 4-5 cm) with visible bile in the ERCP catheter on aspiration. Next, sphincterotomy is performed and stones are removed with a basket or balloon sweep. The number and size of stones extracted are matched with what was seen on initial EUS. A dry sweep across the papilla may indicate stone clearance; however, cholangioscopy or an intraductal ultrasound may occasionally serve as an adjunctive modality to confirm stone clearance.

EUS-assisted ERCP is a radiation-free technique which has demonstrated diagnostic capabilities comparable to those of its standard or radiation-based counterpart (Fig. 1). Polkowski et al conducted the first randomized trial comparing EUS and diagnostic ERCP for detecting biliary stones [27]. In the EUS group, 49 cases were successful, 1 case failed initial EUS, 15 cases subsequently underwent ERCP for bile duct stone treatment, and 6 procedures were required during follow up. In the ERCP group 36 cases were successful, 12 failed initial ERCP, 13 required repeat procedures (EUS or

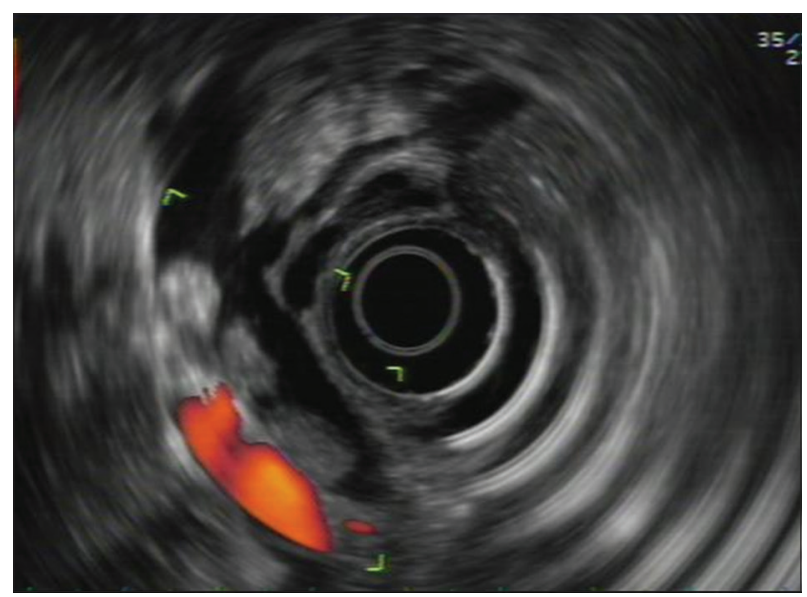

Figure 1 Biliary stones detected on endoscopic ultrasound

Table 1 Radiation dosages received by endoscopists performing endoscopic retrograde cholangiopancreatography (ERCP)

\begin{tabular}{lccc}
\hline Study & Number of ERCPs & Radiation dose received & Anatomy \\
\hline Naidu et al 2005 [16] & 61 & $3.35-5.87 \mathrm{mSv}$ & Whole body \\
Oztas et al 2012 [17] & 110 & $72 \mathrm{uSv}$ & Whole body \\
Sulieman et al 2011 [18] & 57 & $6.2 \mathrm{uSv}$ & Chest \\
& & $3.81 \mathrm{uSv}$ & Forehead \\
& & $27 \mathrm{uSv}$ & Hands \\
& & $5.4 \mathrm{uSv}$ & Thyroid \\
Buls et al 2002 [19] & 54 & $0.30 \mathrm{mSv}$ & Thyroid \\
& & $0.44 \mathrm{mSv}$ & Hands \\
Garg et al 2017 [20] & 187 & $0.34 \mathrm{mSv}$ & Eyes \\
Zagorska et al 2015 [21] & 15 & $2.55-5.35 \mathrm{mSv}$ & Eyes \\
\hline
\end{tabular}


ERCP) after failed or equivocal initial ERCP, and 6 procedures were required during follow up. The study concluded that, among patients with an intermediate pre-test probability for common bile duct (CBD) stones, those who underwent initial evaluation with EUS required fewer ERCP procedures and had fewer complications. However, it should be highlighted that ERCP is currently used as a therapeutic procedure for stone removal, rather than as a diagnostic modality for stone detection.

Vohra et al, in a case series, showed that EUS immediately prior to scheduled ERCP can eliminate the need for ERCP in patients with no evidence of choledocholithiasis on EUS [28]. The study reported the management of 10 pregnant patients, in which CBD stones were identified in $60 \%$ while ERCP was avoided in the remaining $40 \%$. In this study, using the information provided by EUS, patients with confirmed choledocholithiasis underwent ERCP without the use of fluoroscopy. The report cites other studies that found similar diagnostic accuracy when comparing EUS and magnetic resonance cholangiopancreatography $[29,30]$.

Likewise, Shah et al evaluated the feasibility and safety of non-radiation ERCP in non-pregnant patients with uncomplicated stone disease [31]. The study reported successful cannulation without fluoroscopy in 26 of 31 (84\%) patients who underwent non-radiation ERCP. Subsequently, all the patients with successful cannulation had complete stone removal without fluoroscopy. EUS-assisted ERCP eliminated the need for ERCP in 38\% of patients. A novel approach was taken by Mevesa and Pohl, who performed transabdominal ultrasound-assisted ERCP in a patient in the second trimester with gallstones [32]. The case report noted that the papilla was carefully cannulated with a guidewire that was confirmed and controlled using transabdominal ultrasound. While this approach successfully removed gallstones in a pregnant patient without using radiation, information about the method is scarce. Larger studies are needed to confirm the clinical feasibility of transabdominal ultrasound-assisted ERCP.

The major advantage of using EUS-assisted ERCP over its standard counterpart is the potential avoidance of fluoroscopy [25]. Additionally, if no stones are detected on EUS, patients can avoid the need for ERCP [26]. Furthermore, in patients with cholangitis from multiple CBD stones who require emergent ERCP, EUS-assisted ERCP becomes a viable option, especially if a mobile fluoroscopy machine is unavailable [33].

However, there are some limitations to using this modality. Firstly, EUS only shows part of the bile duct, whereas conventional ERCP shows the whole biliary tree. Examination of the bile duct is also limited in patients who have an altered anatomy, such as a prior gastric bypass or Roux-en-Y surgery [34]. Secondly, in a prospective randomized study conducted by Netinatsunton et al, despite similar cannulation success rates using EUS-assisted ERCP and conventional $\operatorname{ERCP}(96.4 \%$ vs. $100 \%, P=0.243)$, the rate of stone clearance in the EUS-assisted ERCP cohort was inferior to that in the ERCP group ( $85.5 \%$ vs. $100 \%, \mathrm{P}=0.002)$ [33]. The results showed that more than 2 stones potentially increase the failure rate of stone clearance in EUS-assisted ERCP. Nevertheless, it is important to note that in this study the mean procedural time and overall adverse events, including post-procedure pancreatitis, were similar in both cohorts.

Most studies evaluating the role of EUS-assisted ERCP were carried out in highly skilled single operating centers, limiting their generalizability to low-volume centers [35]. Additionally, the cost of adding EUS equipment may not be feasible for some centers. Despite these limitations, there remains a role for EUS-assisted ERCP in special situations, such as in pregnant women and patients in the intensive care unit, without having to relocate to the endoscopy suite.

\section{Digital cholangioscopy}

Cholangioscopy has traditionally been used as an adjunctive technique to ERCP, enabling direct visualization, targeted biopsy sampling and lithotripsy [36,37]. In the past, widespread use of cholangioscopy has generally been limited by technological and logistical challenges, including operability [38]. However, the introduction of a digital version of the cholangioscope (SpyGlassDS, Boston Scientific, Natick, Massachusetts), a single-operator cholangioscope, provided better image quality for enhanced visualization using a device that is more user-friendly than first-generation cholangioscopes [39]. Moreover, the newer generations of direct optical cholangioscopes (by Olympus) offer better image quality when compared to SpyGlass (Fig. 2).

Ridtitid et al reported 50 consecutive patients with a CBD stone size $<15 \mathrm{~mm}$ who underwent biliary cannulation and stone removal without fluoroscopy [40]. The study showed similar cannulation rates between DCS and standard ERCP (98\% vs. 98\%), as well as CBD clearance using both methods ( $90 \%$ vs. $98 \%, \mathrm{P}=0.2$ ). Adverse events were also similar between groups. Turowski et al reported a large multicenter study of 250 SpyGlassDS procedures [41], in which lithotripsy guided by single-operator cholangioscopy was performed in 75 cases and was successful in 71 (95\%). An adverse event occurred in $33 / 250$ patients $(13.2 \%)$, while a serious adverse event occurred in $1 / 250$ patients $(0.4 \%)$. The incidence of cholangitis was $1 \%$ $(1 / 102)$ after peri-interventional administration of antibiotics and $12.8 \%(19 / 148)$ without antibiotic prophylaxis $(\mathrm{P}<0.001)$.

Barakat et al reported that the DCS was comparable to conventional ERCP in the management of noncomplex

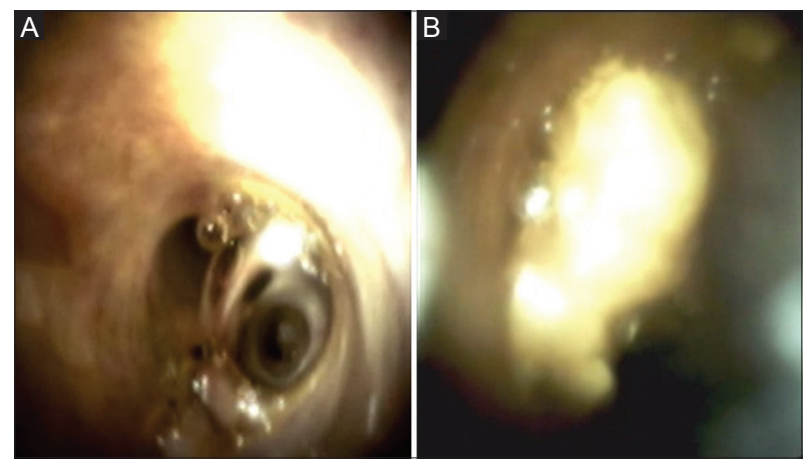

Figure 2 (A) Normal biliary duct using the digital SpyGlass system. (B) Biliary stone using the digital SpyGlass system 
choledocholithiasis, with similar success and adverse events [42]. The study performed fluoroscopy-free biliary cannulation, sphincterotomy, followed by cholangioscopy to establish the location, number and sizes of stones and to document the distance from ampulla to bifurcation in order to guide balloon advancement. Next, bile stones were extracted using a marked balloon catheter advanced to the bifurcation and inflated to the bile duct diameter, documented on prior imaging. Stone clearance was confirmed with repeat cholangioscopy. The study results noted that fluoroscopy-free biliary cannulation was successful in all 40 patients (100\%). Discrete stones were visualized in 31 patients and stone debris/ sludge in 8 patients. Fluoroscopy-free stone/debris/sludge extraction was successful in all these patients. Brief fluoroscopy was used in 2 patients (5\%) to confirm stone clearance. The absence of any stone/debris/sludge was noted in 1 patient. Mild pancreatitis was noted in 2 patients (5\%) and bleeding in $1(2.5 \%)$. The above studies demonstrate that the DCS system can potentially be used for treating biliary obstruction without necessitating fluoroscopy.

DCS involves biliary cannulation using a sphincterotome or catheter without fluoroscopy. Successful cannulation is confirmed by easy advancement of a guidewire without any resistance, as well as the visualization of bilious aspirate in contrast to the clear appearance of pancreatic fluid. If the pancreatic duct is cannulated inadvertently, the guidewire is left in place to define the pancreatic duct entry. This enables the correct orientation of the bile duct for successful cannulation using the double-wire technique [42]. Next, with confirmed biliary cannulation, biliary sphincterotomy is performed, followed by cholangioscopy to define the anatomy of the biliary duct. The number and positions of stones are also assessed at this stage. A balloon catheter is advanced over the guidewire and balloon sweeps are performed repeatedly to remove the stones. Electrohydraulic lithotripsy or laser-directed lithotripsy can be performed for complex stones based on their size relative to the distal bile duct [43]. Finally, the DCS system can be advanced into the CBD to confirm clearance of all stones from the bile duct.

DSC offers some advantages over other non-radiation ERCP techniques such as EUS-assisted approaches. Firstly, the learning curve for cholangioscopy is shorter compared to EUS and does not require subsequent training beyond ERCP training. Secondly, cholangioscopy provides visual assessment of the guidewire location in real time and can steer guidewire advancement into the hepatic ducts for the extraction of proximal stones [42]. Thirdly, the feasibility of doing an electrohydraulic or other lithotripsy for complex stones also provides additional benefit [44]. Lastly, DSC has significantly better image quality compared to prior cholangioscopes.

Despite these advantages, there are potential drawbacks associated with the use of DCS. There is a possible risk of an unwarranted sphincterotomy during DCS if spontaneous passage of biliary stones occurs [42]. This can usually be avoided with conventional fluoroscopy-based ERCP or EUS-assisted therapy. Lenze et al reported that while singleoperator DCS is associated with a high technical success rate, it is accompanied by a high rate (16\%) of adverse events, including pancreatitis, cholangitis, and major bleeding [45]. Furthermore, the cost-effectiveness of DCS remains unknown and may limit its adoption. Further model-based cost-utility analysis is needed to estimate the mean cost and outcome per patient associated with use of DCS versus EUS-assisted ERCP and conventional ERCP.

\section{Concluding remarks}

EUS-assisted ERCP and DCS are viable radiation-free alternatives to conventional ERCP for managing biliary stones. For other conditions, such as strictures, leaks, and clots, nonradiation ERCP is limited in its current forms and technologies and its role in managing these conditions remains unclear. Furthermore, while EUS-assisted ERCP is associated with a lower rate of adverse events, it requires exceptional training in both EUS and ERCP and may be limited by the number of biliary stones. DCS represents a more user-friendly approach with enhanced imaging, but has a higher rate of adverse events. Future studies should include a head-to-head comparison against conventional ERCP through randomized controlled trials. This will ultimately lead to the development of strategic algorithms and established roles for the removal of biliary stones. Additionally, studies comparing their cost effectiveness are also warranted and may have an impact on hospital investments, while reducing radiation exposure in patients and endoscopic personnel.

\section{References}

1. Adler DG, Baron TH, Davila RE, et al; Standards of Practice Committee of American Society for Gastrointestinal Endoscopy. ASGE guideline: the role of ERCP in diseases of the biliary tract and the pancreas. Gastrointest Endosc 2005;62:1-8.

2. Hawes RH. Diagnostic and therapeutic uses of ERCP in pancreatic and biliary tract malignancies. Gastrointest Endosc 2002;56:S201-S205.

3. Moffatt DC, Yu BN, Yie W, Bernstein CN. Trends in utilization of diagnostic and therapeutic ERCP and cholecystectomy over the past 25 years: a population-based study. Gastrointest Endosc 2014;79:615-622.

4. Zeng HZ, Liu Q, Chen HL, et al. A pilot single-center prospective randomized trial to assess the short-term effect of a flashing warning light on reducing fluoroscopy time and radiation exposure during ERCP. Gastrointest Endosc 2018 Mar 17 [Epub ahead of print].

5. Katsinelos P, Gatopoulou A, Gkagkalis S, et al. A prospective analysis of factors influencing fluoroscopy time during therapeutic ERCP. Ann Gastroenterol 2012;25:338-344.

6. Kim E, McLoughlin M, Lam EC, et al. Prospective analysis of fluoroscopy duration during ERCP: critical determinants. Gastrointest Endosc 2010;72:50-57.

7. Jorgensen JE, Rubenstein JH, Goodsitt MM, Elta GH. Radiation doses to ERCP patients are significantly lower with experienced endoscopists. Gastrointest Endosc 2010;72:58-65.

8. Binmoeller KF, Nett A. ERC: Time to take the lead off? Gastrointest Endosc 2017;86:1066-1069. 
9. Amis ES Jr, Butler PF, Applegate KE, et al; American College of Radiology. American College of Radiology white paper on radiation dose in medicine. J Am Coll Radiol 2007;4:272-284.

10. Campbell N, Sparrow K, Fortier M, Ponich T. Practical radiation safety and protection for the endoscopist during ERCP. Gastrointest Endosc 2002;55:552-557.

11. Brown KR, Rzucidlo E. Acute and chronic radiation injury. J Vasc Surg 2011;53(1 Suppl):15S-21S.

12. Larkin CJ, Workman A, Wright RE, Tham TC. Radiation doses to patients during ERCP. Gastrointest Endosc 2001;53:161-164.

13. Cairns RA, Harris IS, Mak TW. Regulation of cancer cell metabolism. Nat Rev Cancer 2011;11:85-95.

14. Ainsbury EA, Bouffler SD, Dörr W, et al. Radiation cataractogenesis: a review of recent studies. Radiat Res 2009;172:1-9.

15. International Commission on Radiological Protection Statement on Tissue Reactions. Report no. ICRP 4825-3093-1464. ICRP: Ottawa, ON, 2011.

16. Naidu LS, Singhal S, Preece DE, Vohrah A, Loft DE. Radiation exposure to personnel performing endoscopic retrograde cholangiopancreatography. Postgrad Med J 2005;81:660-662.

17. Oztas E, Parlak E, Kucukay F, et al. The impact of endoscopic retrograde cholangiopancreatography education on radiation exposure to experienced endoscopist: 'trainee effect'. Dig Dis Sci 2012;57:1134-1143.

18. Sulieman A, Paroutoglou G, Kapsoritakis A, et al. Reduction of radiation doses to patients and staff during endoscopic retrograde cholangiopancreatography. Saudi J Gastroenterol 2011;17:23-29.

19. Buls N, Pages J, Mana F, Osteaux M. Patient and staff exposure during endoscopic retrograde cholangiopancreatography. $\mathrm{Br} J$ Radiol 2002;75:435-443.

20. Garg MS, Patel P, Blackwood M, et al. Ocular radiation threshold projection based off of fluoroscopy time during ERCP. Am J Gastroenterol 2017;112:716-721.

21. Zagorska A, Romanova K, Hristova-Popova J, Vassileva J, Katzarov $\mathrm{K}$. Eye lens exposure to medical staff during endoscopic retrograde cholangiopancreatography. Phys Med 2015;31:781-784.

22. Coté GA. The provision of ERCP services in the United States is a radiating concern. Gastrointest Endosc 2015;81:399-401.

23. Pedrosa MC, Farraye FA, Shergill AK, et al; ASGE Technology Committee. Minimizing occupational hazards in endoscopy: personal protective equipment, radiation safety, and ergonomics. Gastrointest Endosc 2010;72:227-235.

24. Binmoeller KF, Katon RM. Needle knife papillotomy for an impacted common bile duct stone during pregnancy. Gastrointest Endosc 1990;36:607-609.

25. Petrov MS, Savides TJ. Systematic review of endoscopic ultrasonography versus endoscopic retrograde cholangiopancreatography for suspected choledocholithiasis. $\mathrm{Br} J$ Surg 2009;96:967-974.

26. Lee YT, Chan FK, Leung WK, et al. Comparison of EUS and ERCP in the investigation with suspected biliary obstruction caused by choledocholithiasis: a randomized study. Gastrointest Endosc 2008;67:660-668.

27. Polkowski M, Regula J, Tilszer A, Butruk E. Endoscopic ultrasound versus endoscopic retrograde cholangiography for patients with intermediate probability of bile duct stones: a randomized trial comparing two management strategies. Endoscopy 2007;39:296303.

28. Vohra S, Holt EW, Bhat YM, Kane S, Shah JN, Binmoeller KF. Successful single-session endosonography-based endoscopic retrograde cholangiopancreatography without fluoroscopy in pregnant patients with suspected choledocholithiasis: a case series. J Hepatobiliary Pancreat Sci 2014;21:93-97.
29. Meeralam Y, Al-Shammari K, Yaghoobi M. Diagnostic accuracy of EUS compared with MRCP in detecting choledocholithiasis: a meta-analysis of diagnostic test accuracy in head-to-head studies. Gastrointest Endosc 2017;86:986-993.

30. Verma D, Kapadia A, Eisen GM, Adler DG. EUS vs MRCP for detection of choledocholithiasis. Gastrointest Endosc 2006;64:248-254.

31. Shah JN, Bhat YM, Hamerski CM, Kane SD, Binmoeller KF. Feasibility of non-radiation EUS-based ERCP in patients with uncomplicated choledocholithiasis (with video). Gastrointest Endosc 2016;84:764-769.

32. Meves V, Pohl J. Trans-abdominal ultrasound guided ERC in a pregnant woman with bile duct stones. Video Journal and Encyclopedia of GI Endoscopy 2014;2:9-11.

33. Netinatsunton N, Sottisuporn J, Attasaranya S, et al. Prospective randomized trial of EUS-assisted ERCP without fluoroscopy versus ERCP in common bile duct stones. Gastrointest Endosc 2017;86:1059-1065.

34. Wilson JA, Hoffman B, Hawes RH, Romagnuolo J. EUS in patients with surgically altered upper GI anatomy. Gastrointest Endosc 2010;72:947-953.

35. Binmoeller KF. Nonradiation, endoscopic ultrasound-based endoscopic retrograde cholangiopancreatography. Gastroenterol Hepatol (N Y) 2017;13:58-61.

36. Ramchandani M, Reddy DN, Gupta R, et al. Role of single-operator peroral cholangioscopy in the diagnosis of indeterminate biliary lesions: a single-center, prospective study. Gastrointest Endosc 2011;74:511-519.

37. Siddiqui AA, Mehendiratta V, Jackson W, Loren DE, Kowalski TE, Eloubeidi MA. Identification of cholangiocarcinoma by using the Spyglass Spyscope system for peroral cholangioscopy and biopsy collection. Clin Gastroenterol Hepatol 2012;10:466-471.

38. Kalaitzakis E, Webster GJ, Oppong KW, et al. Diagnostic and therapeutic utility of single-operator peroral cholangioscopy for indeterminate biliary lesions and bile duct stones. Eur $J$ Gastroenterol Hepatol 2012;24:656-664.

39. Mizrahi M, Wang Y, Jonah $C$, et al. Light at the end of the tunnel: comparative effectiveness of second-generation digital SpyGlass with first-generation SpyGlass (R) cholangioscopy. Am J Gastroenterol 2015;110:S25.

40. Ridtitid W, Luangsukrerk T, Angsuwatcharakon P, et al. Uncomplicated common bile duct stone removal guided by cholangioscopy versus conventional endoscopic retrograde cholangiopancreatography. Surg Endosc 2018;32:2704-2712.

41. Turowski F, Hugle U, Dormann A, et al. Diagnostic and therapeutic single-operator cholangiopancreatoscopy with SpyGlassDS ${ }^{\mathrm{m}}$ : results of a multicenter retrospective cohort study. Surg Endosc 2018 Mar 12 [Epub ahead of print].

42. Barakat MT, Girotra M, Choudhary A, Huang RJ, Sethi S, Banerjee S. A prospective evaluation of radiation-free direct solitary cholangioscopy for the management of choledocholithiasis. Gastrointest Endosc 2018;87:584-589.

43. Bhandari S, Sanghvi K, Sharma A, Bondade N, Maydeo A. Single-operator cholangioscopy-guided holmium laser lithotripsy: the new-age "rescue" lithotripsy. Gastrointest Endosc 2016;83:1035-1036.

44. Terheggen G, Neuhaus H. New options of cholangioscopy. Gastroenterol Clin North Am 2010;39:827-844.

45. Lenze F, Bokemeyer A, Gross D, Nowacki T, Bettenworth D, Ullerich H. Safety, diagnostic accuracy and therapeutic efficacy of digital single-operator cholangioscopy. United European Gastroenterol J 2018 March 8 [Epub ahead of print]. 